\title{
INVESTIGACIÓN, ADECUACIÓN Y MUSEALIZACIÓN DEL SANTUARIO PROTOHISTÓRICO DE CANCHO ROANO (ZALAMEA DE LA SERENA, BADAJOZ)
}

\author{
RESEARCH AND ADAPTATION FOR PUBLIC ACCESS TO THE PROTOHISTORIC \\ SANCTUARY OF CANCHO ROANO (ZALAMEA DE LA SERENA, BADAJOZ)
}

SEBASTIÁN CELESTINO PÉREZ (*)

\section{RESUMEN}

En los últimos años se están llevando a cabo una serie de intervenciones en el santuario protohistórico de Cancho Roano que desembocarán en los próximos meses en su definitiva apertura al público. Todos estos trabajos se han elaborado bajo sendos proyectos financiados con fondos europeos, por las administraciones públicas y por la iniciativa privada, pero sin que se haya abandonado en ningún momento el objetivo científico: así, se han realizado las excavaciones de los edificios inferiores y de las estructuras arquitectónicas del exterior, se ha levantado una nueva cubierta para proteger las nuevas zonas exhumadas, se han acometido obras de restauración, consolidación y restitución de las estructuras arquitectónicas, se ha llevado a cabo la compra de terrenos y la realización de un nuevo cierre del espacio protegido y, por último, se están finalizando las obras de un Centro de Interpretación junto al enclave para explicar al visitante el complejo monumental que van a visitar. El propio santuario ha servido de revulsivo para potenciar otros yacimientos de la zona y crear una infraestructura en la comarca cuyo objetivo es impulsar el turismo cultural.

\begin{abstract}
In recent years work has been done on the protohistoric sanctuary of Cancho Roano in preparation for its opening to the public in the coming months. All these activities have been large financed by two different projects sponsored by European income, and public funds and private enterprise,

(*) Dpto. de Prehistoria, Instituto de Historia. CSIC. Duque de Medinaceli, 6. 28014 Madrid. Correo electrónico: scelestino@ceh.csic.es

El artículo fue remitido en su versión final el 11-X-2000.
\end{abstract}

without forgetting scientific research goals. In this way, archaeological excavations have been finished both inside the buildings of the complex and on the outside structures; a new covering was erected last year to protect the archaeological remains; although restoration activities and the restitution of a few structures were finished a year ago. On the other hand, some adjoining private properties have been acquired by public institutions while the enclosure of the site was already finished; and finally an Interpretation Centre has been built to explain the complex to visitors. The sanctuary has been the start of research on many other sites in surrounding areas and has created a regional infrastructure aimed at stimulating cultural tourism.

Palabras Clave: Protohistoria. Proyecto de Investigación. Adecuación. Restauración. Cubierta. Financiación. Centro de Interpretación. Musealización. Turismo cultural.

Key words: Protohistory. Archaeological resource management. Interpretation Centre. Research project.

\section{INTRODUCCIÓN}

En el invierno de 1992, tras cinco años de intensos trabajos arqueológicos en el monumento de Cancho Roano (Fig. 1) gracias al sensible aumento de los presupuestos destinados al yacimiento, la Dirección General de Patrimonio de la Consejería de Cultura de la Junta de Extremadura me encargó la elaboración de un Plan Director donde se contemplasen todas las necesidades del enclave para proceder, en un plazo de cuatro años, a su definitiva apertura al público. Este ambicioso plan fue presentado oficialmente al año siguiente, pero no fue definitivamente asumido hasta 1995, año en el que, 


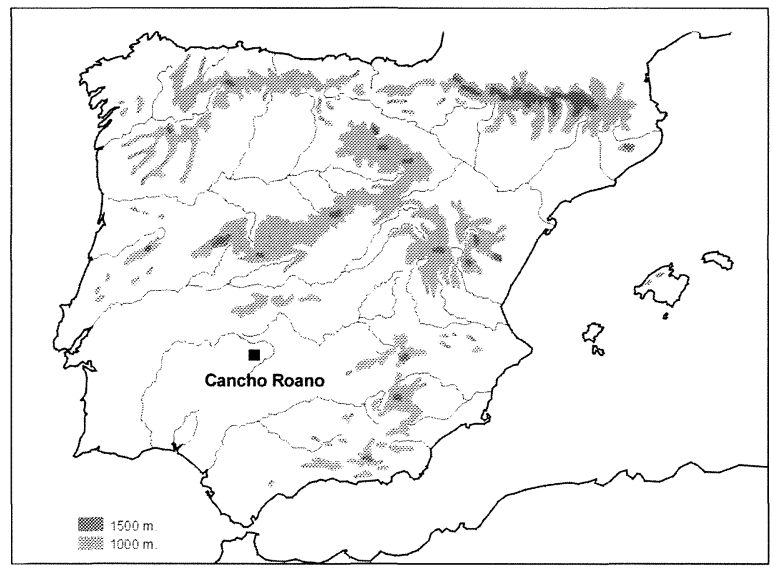

Fig. 1. Localización del santuario de Cancho Roano, en Zalamea de la Serena, provincia de Badajoz, en la Península Ibérica.

paradójicamente, no hubo excavaciones arqueológicas en toda Extremadura, paréntesis que fue aprovechado para hacer una especie de catarsis colectiva de los arqueólogos que trabajábamos en la región, auspiciada por la propiaAdministración, donde se intentó elaborar, tras unas jornadas de reflexión organizadas en Trujillo, un "libro blanco" cuyo objetivo era crear una base sólida sobre la que desarrollar el rico patrimonio arqueológico de la región.Aunque la intención era digna de encomio, el resultado fue decepcionante, pues a la autocomplacencia de la Administración se interpuso una corriente crítica, minoritaria pero contundente, que abogaba por la protección de los Proyectos de Investigación en detrimento de las excavaciones dispersas y carentes de una estrategia para conocer las pautas del poblamiento pretérito o faltas de un discurso histórico que, por norma general, eran las que predominaban en aquel momento.Y parece que sin un reconocimiento explícito, esa corriente crítica se impuso claramente, aunque debido más a la influencia que ejercieron las normativas de otras Comunidades Autónomas, fundamentalmente la andaluza, que al denuedo de los investigadores extremeños más críticos.

Fruto de la nueva estrategia elaborada para encauzar el patrimonio arqueológico extremeño fue el diseño de unas normas de actuación que desembocaron en la elección de los yacimientos más señeros de la comunidad para desarrollar en ellos actuaciones cuyo fin, además de la investigación, era acondicionarlos para darlos a conocer al público, acuñándose para la ocasión un término tan ambiguo gramaticalmente como exitoso entre la clase política: la puesta en valor. Para ello se escogieron los enclaves con mayor tradición en la investigación arqueológica que, además, reunieran algunos requisitos mínimos que justificaran la inversión que se pretendía realizar en ellos, como podía ser su monumentalidad, su accesibilidad o su situación privilegiada dentro de las rutas turísticas de la región, circunstancias que podrían atraer además a la iniciativa privada. Las consecuencias inmediatas han sido, por un lado, la selección de un número muy restringido de yacimientos que hoy se excavan en la región y, por el otro, la desaparición de los trabajos en sitios arqueológicos que, por no tener vistosas estructuras arquitectónicas, carecer de materiales atrayentes o estar apartados de la actual red de carreteras, están lejos de poder ser valorados por los potenciales turistas culturales. Buscar una armonía entre las dos alternativas no debería suponer la renuncia a los principios fundamentales del proyecto arqueológico de la región. En el primer caso se persigue que, al menos culturalmente, la inversión sea rentable, haciendo partícipes de las investigaciones y de los hallazgos a todos los interesados; la segunda sigue siendo una necesidad evidente tanto para encauzar la investigación arqueológica como para promocionar a las nuevas generaciones en esta difícil y dura disciplina.

En este ambiente se han desarrollado los trabajos de Cancho Roano, donde se están llevando a cabo en los últimos años varios proyectos, tanto de investigación como de adecuación y musealización del yacimiento que, además, pueden servir de ejemplo para ilustrar las dos etapas aludidas.

\section{LOS AVATARES DE UN MONUMENTO SINGULAR}

Cuando Maluquer comenzó en 1978 las excavaciones en el enclave protohistórico, ubicado en el término municipal de Zalamea de la Serena, al Sureste de la provincia de Badajoz, ya intuyó que se trataba de un monumento con la suficiente enjundia arqueológica como para no plantear una simple intervención al uso en aquella época (Lám. I). Por ello, optó por organizar tres equipos que acometiesen diferentes tareas en el yacimiento: uno de la Subdirección de Arqueología del Ministerio de Cultura que él dirigía en ese momento, otro compuesto por arqueólogos extremeños y uno formado por profesores y estudiantes de la Universidad de Barcelona. 


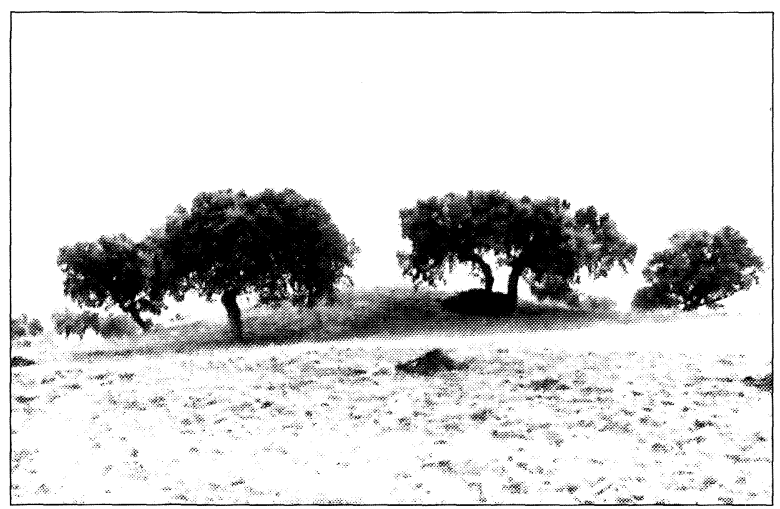

Lám. I.Vista del túmulo de Cancho Roano inmediatamente antes de la intervención arqueológica de 1978.

La experiencia, desgraciadamente, no fue todo lo positiva que cabría esperar, por lo que las siguientes campañas las desempeñó casi exclusivamente con personal procedente de su departamento universitario, salvo alguna excepción de la que se benefició, por ejemplo, el que suscribe estas páginas.

Pero si el problema arqueológico estaba relativamente solucionado a pesar de los escasos presupuestos que se destinaban al yacimiento, paliados en gran medida por la infraestructura que ofrecía la propia Universidad catalana así como por el trabajo de todos los que estábamos implicados en el Programa de Investigación Protohistórica, comenzaba a ser acuciante la necesidad de proteger y conservar las potentes paredes de adobe que se habían exhumado en los últimos años (Lám. II), de hasta $4 \mathrm{~m}$ de altura en algún caso, así como los suelos de arcilla o pizarra, los acerados de cantos rodados, etc. Las fuertes lluvias otoñales de la zona estaban deteriorando peligrosa y rápidamente uno de los edificios mejor conservados de nuestra Protohistoria. A la cada vez mayor escasez de recursos destinados al monumento, tanto humanos como técnicos, se le unía las reticencias de uno de los dueños del terreno, radicalmente opuesto a que se excavara parte del yacimiento si la Administración no accedía a adquirirlo.

Esta desesperada situación se mantuvo hasta 1984, y ello a pesar de las continuas diligencias empleadas por Maluquer en la recién creada administración autonómica extremeña. En ese año se planteó incluso la posibilidad de terminar una de las habitaciones del sector septentrional del edificio para después proceder a tapar por completo el monumento y evitar así su destrucción. Pero el destino, en forma de flamante Directora General de Pa-

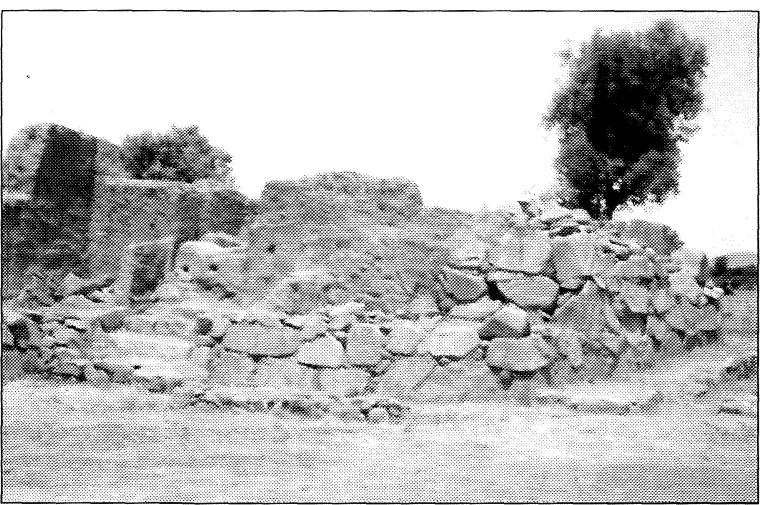

Lám. II. Aspecto del santuario de Cancho Roano tras la campaña de 1985 .

trimonio, acudió en auxilio de Cancho Roano. En efecto, una vez instituido el nuevo gobierno autonómico, se creó la Consejería de Cultura con tres direcciones generales, una de ellas dedicada al patrimonio arquitectónico y arqueológico, nombrándose para dirigirla a la entonces catedrática de Prehistoria de la Universidad de Extremadura Milagros Gil-Mascarell, ex alumna de Maluquer y, sobre todo, persona sensibilizada con los avatares arqueológicos de la región. No podemos olvidar que una de sus primeras decisiones fue encargar un proyecto de intervención urgente en el yacimiento en el que se contemplaba la construcción de una cubierta para preservar los restos constructivos (Lám. III), la expropiación de los terrenos ocupados por el edificio hasta ese momento conocido y el cierre de la propiedad adquirida. Todas estas actuaciones se llevaron a cabo en 1986, coincidiendo con la declaración de Bien de Interés Cultural del enclave. Sin embargo, la fuerte inversión destinada a desarrollar el proyecto obligó a restringir aún más la intervención arqueológica, y así, en las campañas de 1986 y 1987, el equipo lo componíamos tan sólo dos personas, con el profesor Maluquer ya muy enfermo y preocupado por resolver definitivamente algunos detalles de la excavación.

En el año 1988 se produjeron dos hechos que cambiarían radicalmente la historia del yacimiento; en primer lugar, la muerte del profesor Maluquer tan solo unos días antes de comenzar la campaña, lo que obligó a reorganizar el equipo y los objetivos arqueológicos, hasta ese momento muy centrados en el edificio principal; en segundo lugar, la entrada de la inversión privada en el yacimiento, revulsivo que permitió sensibilizar definitivamente a las diferentes administraciones regionales. Esta acci- 


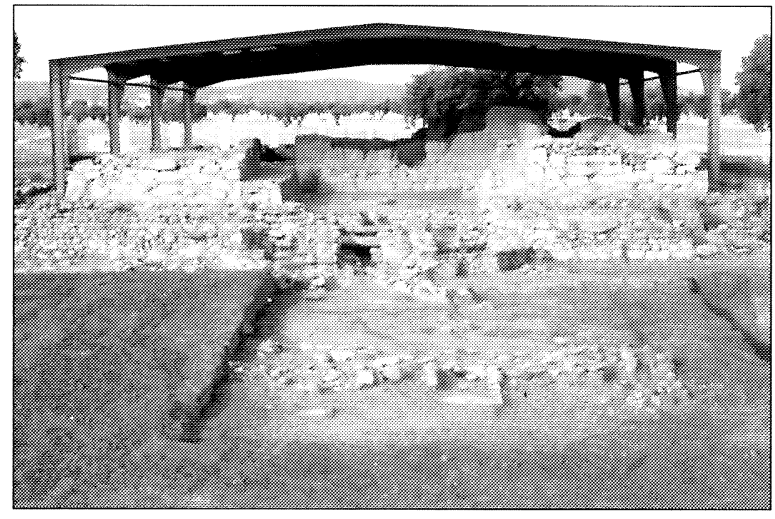

Lám. III. Vista general de Cancho Roano en 1987, una vez instalada la primera cubierta de protección.

dentada campaña de 1988 fue recompensada por los magníficos hallazgos de las ofrendas que se exhumaron en las nuevas habitaciones o capillas que rodeaban por completo el monumento, rematadas en el sector oriental por la muralla y las torres que cerraban lo que ahora podía definirse sin ambages como un gran complejo arquitectónico. Los nuevos descubrimientos obligaron a prolongar el proyecto arqueológico, aunque no repercutieron significativamente en el aumento de la inversión. Pero un hecho extraordinario, que creo conveniente relatar sucintamente en estas páginas, iba a suponer un cambio radical en la trayectoria investigadora del yacimiento.

En efecto, atraído por las noticias publicadas en la prensa sobre los últimos hallazgos de Cancho Roano, se interesó por el sitio un singular empresario de Badajoz, Bartolomé Gil Santacruz, conocido por su mecenazgo cultural en la región, quien tras visitar el lugar y mostrar su entusiasmo por los restos exhumados, puso a nuestra disposición los medios económicos necesarios para acometer una intensa campaña de excavación, así como los medios técnicos y humanos imprescindibles para desarrollar otras actividades hasta ese momento imposibles de abordar. Pero además, su inversión en los años siguientes, hasta 1994, provocó la reacción inmediata de la administración regional, que se vio obligada a igualar la financiación privada. Por lo tanto, se pasó de la penuria a la holgura presupuestaria, lo que supuso, por otra parte, una gran labor de gestión para encauzar los trabajos de los diferentes equipos españoles y extranjeros que comenzaron a participar, tanto en las excavaciones, como en los estudios del ingente material acumulado en los fondos del Museo de Badajoz, la analítica de los restos orgánicos e inorgánicos recuperados o el exhaustivo examen de los importantes vestigios arquitectónicos.

El mecenazgo de un particular y la responsabilidad de la administración han generado el gran complejo monumental que ahora conservamos, porque la llamada desesperada de Maluquer primero y mía después, para que empresas de la zona o entidades bancarias de la región invirtieran en el monumento siempre cayeron en saco roto; es más, alguna de estas últimas siguen cobrando suculentas comisiones por las inevitables dilaciones en los pagos, pero sin embargo son osados a la hora de optar a poner sus logotipos en las portadas de los libros a cambio de ridículas contrapartidas cuando el gran esfuerzo ya se ha realizado.

\section{EL PLAN DIRECTOR DE CANCHO ROANO}

La nueva dinámica creada en el yacimiento necesitó de una dedicación casi exclusiva para llevar a buen término el ambicioso proyecto presentado. Campañas arqueológicas de hasta tres y cuatro meses, el estudio de ingentes cantidades de material de la más variada gama y tipología, el análisis de esos materiales y de otros restos para extraer la mayor información posible del lugar, la restauración de las piezas más significativas o la elaboración de programas informáticos para controlar los diferentes aspectos arquitectónicos del monumento son algunos de los trabajos realizados. Pero todos estas actuaciones, desarrolladas entre los años 1988 y 1994, generaron una serie de necesidades y problemas que obligaron a elaborar un Plan Integral del yacimiento donde se exponían tanto las actuaciones que se precisaban con urgencia para conservar el complejo monumental, como las necesidades puramente arqueológicas para continuar impulsando la investigación en el yacimiento. Los siguientes apartados presentan los puntos que se acometían en el mencionado Plan integral.

\subsection{La actuación arqueológica}

Las dilatadas campañas de excavación de inicios de los años noventa dieron como resultado el descubrimiento de nuevos restos constructivos que aumentaron sensiblemente la superficie arqueológica susceptible de ser protegida. Así, se exhuma- 
ron las ricas estancias que rodeaban por completo al monumento principal, se finalizaron igualmente los trabajos en la zona oriental del yacimiento, donde se dispone la entrada del complejo monumental y donde se organiza la muralla y las torres que flanquean su acceso (Fig. 2). Asimismo, se acometió la excavación de una zona del foso que encinta por completo el enclave, si bien, la enorme superficie de éste impedía acometer su excavación a corto plazo, por lo que se decidió la paralización de estos trabajos hasta obtener un presupuesto específico que permitiera su excavación integral.

Por lo tanto, con estos trabajos, y a expensas de acometer en el futuro la excavación total del foso, una parte de los responsables culturales de la región apostaron por dar por concluidas las investigaciones en Cancho Roano y centrar así todos los esfuerzos en actuaciones concretas que permitieran su adecuación para facilitar cuanto antes la visita pública. Pero los hallazgos de los edificios inferiores, también en aceptables condiciones de conservación, nos obligaron a reivindicar la continuación de las investigaciones y a prolongar el proyecto hasta que se concluyeran los trabajos arqueológicos para disponer así de un perfecto conocimiento de su proceso histórico y, sólo después, acometer las obras necesarias para su «puesta en valor». Por ello, en el Plan Integral se proyectaba la excavación sistemática de toda la superficie del monumento principal para así poder recuperar las estructuras arquitectónicas de los edificios inferiores y elaborar la consiguiente planimetría que nos permitiera proceder a su estudio (Lám. IV). El trabajo a desarrollar era desde luego muy complicado, pues había que levantar todos los suelos y otras estructuras significativas de sendos monumentos, además de las dificultades técnicas derivadas de tan laboriosa intervención, donde se hacía necesario entibar y apuntalar los cimientos del último edificio para alcanzar con éxito el nivel geológico del yacimiento y extraer toda la documentación guardada en su potente estratigrafía.

Por último, como se ha apuntado, también en el Plan Integral se contemplaba la excavación del foso que rodeaba por completo al complejo monumental. Estos trabajos deberían llevarse a cabo en un plazo de cuatro años y con unos amplios equipos de arqueólogos en campañas de varios meses, no sólo por la enorme superficie a excavar, sino por la ingente cantidad de material depositado en su interior y que debería estudiarse en paralelo a la propia ex-

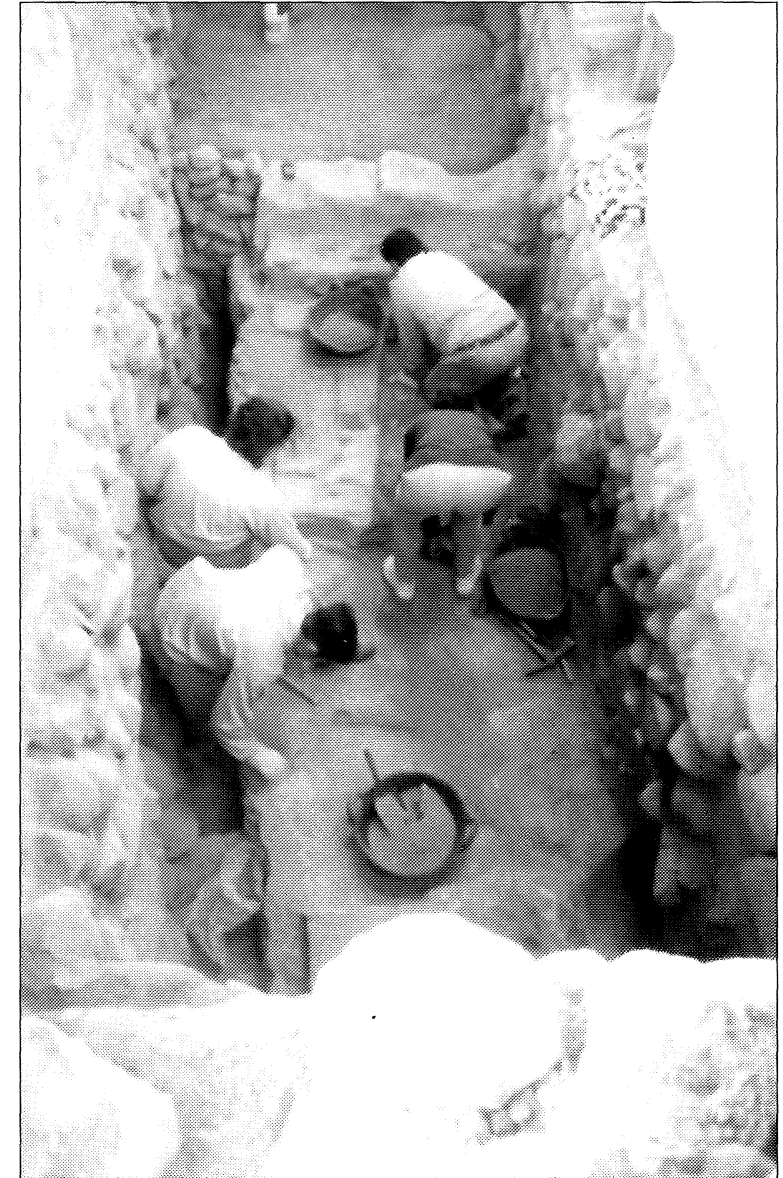

A

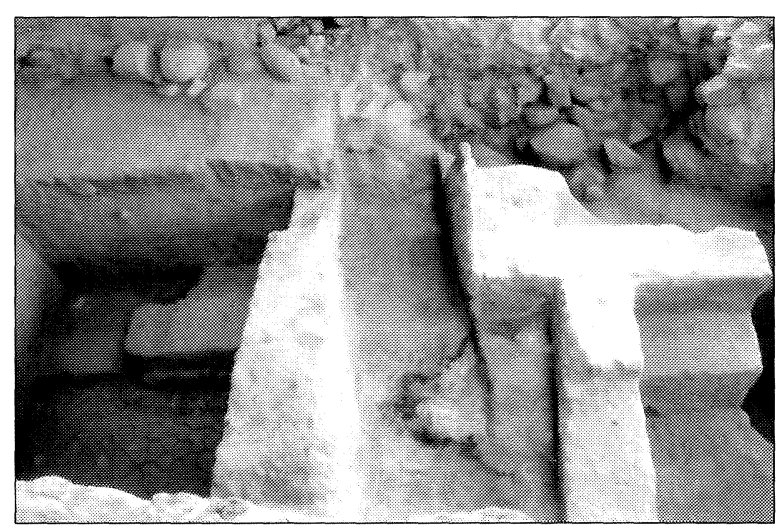

B

Lám IV. A) Proceso de excavación de los santuarios Cancho Roano "B" y Cancho Roano "C". B) Restos de la fachada principal del santuario "B".

cavación para así disponer de todos los datos posibles una vez finalizados los trabajos. El presupuesto sobrepasaba con creces las posibilidades presupuestarias de la Dirección General de Patrimonio, 


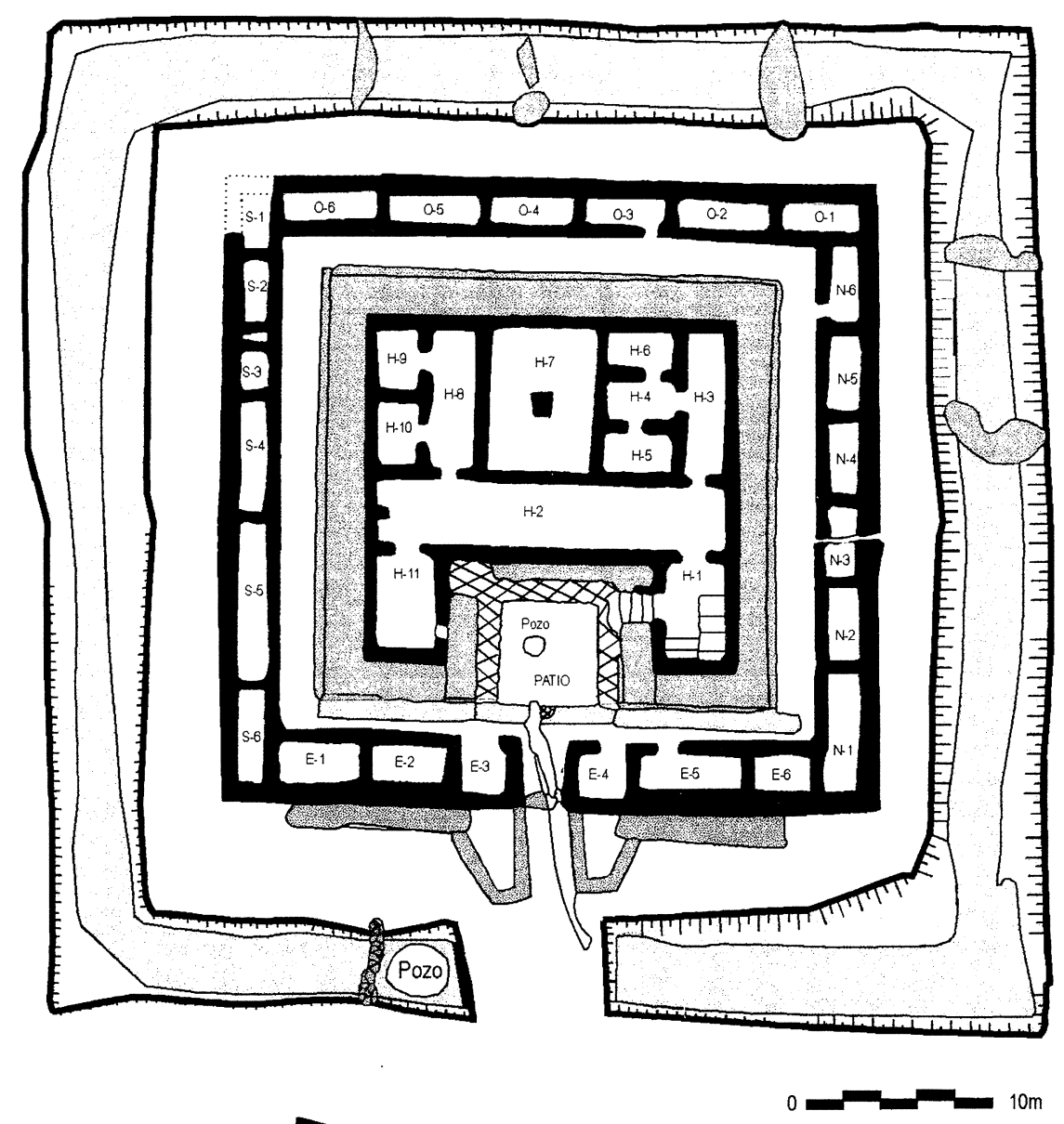

\section{N}

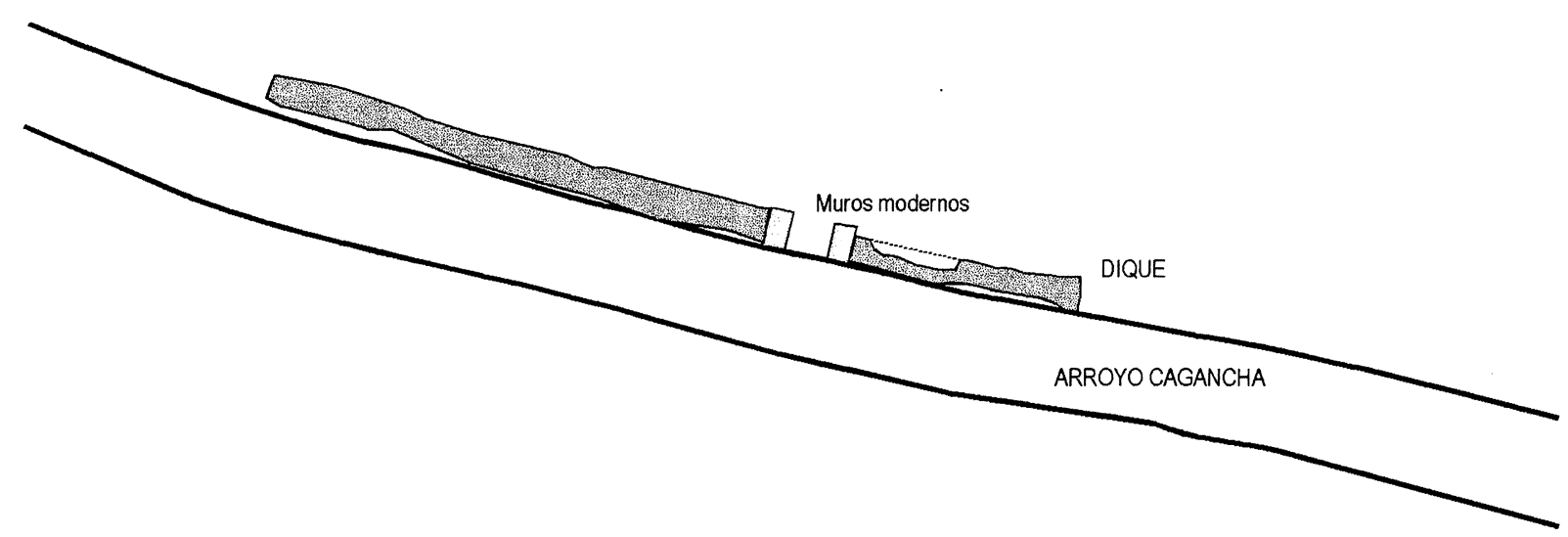

Fig. 2. Planta general del complejo monumental de Cancho Roano en su última fase constructiva.

T. P., 57, n. ${ }^{\circ} 2,2000$ 


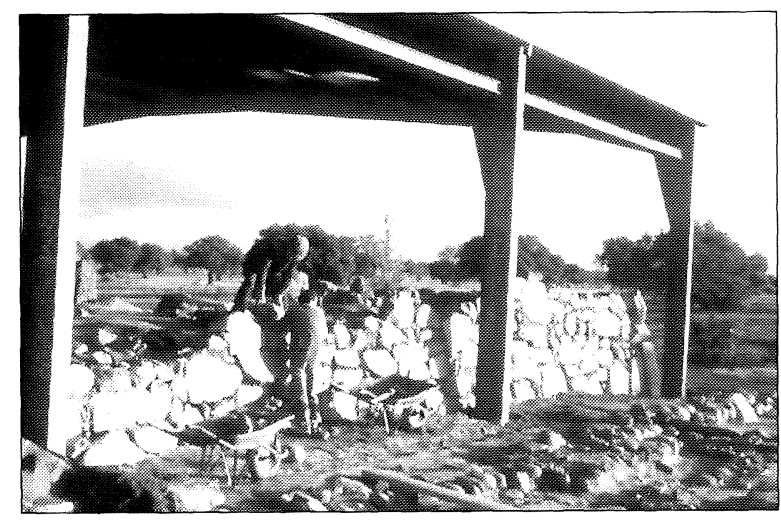

A

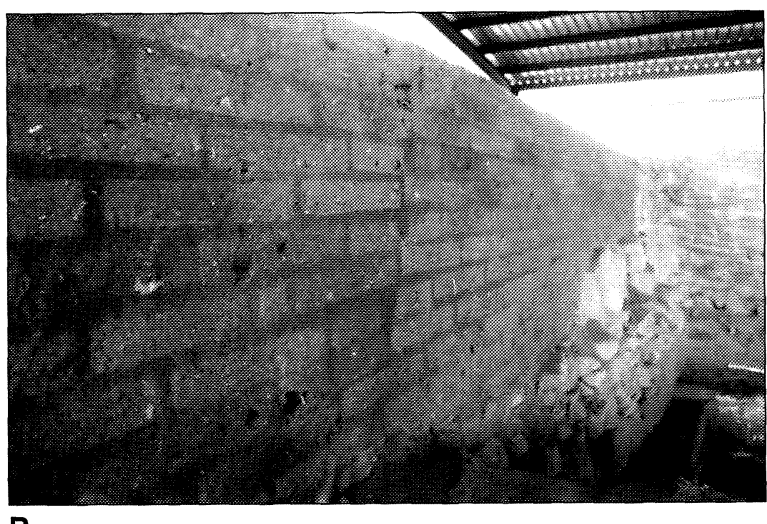

B

Lám.V. A) Obras de reconstrucción de la terraza meridional del edificio principal deCancho Roano. B) Reconstrucción del muro de adobes del sector meridional; al fondo se puede apreciar el alzado de adobe original.

pero no se rechazó la actuación, aunque a expensas de encontrar financiación ajena a la Junta de Extremadura.

\subsection{La adecuación del monumento y su entorno}

La gran superficie excavada en los últimos años, donde se organizaban nuevas estructuras arquitectónicas de piedra y adobe, además de suelos y rampas de arcilla roja, canales, pozos, pavimentos de pizarra, etc., generó dos necesidades ineludibles: la ampliación de la cubierta levantada en 1986 y la compra de nuevos terrenos que permitieran tanto la excavación total del foso como la construcción de un nuevo cierre del yacimiento.

De suma importancia era igualmente la intervención en los alzados de adobe que se hallaban protegidos bajo la cubierta. Es evidente que la gran protección metálica había evitado el rápido deterioro de los ladrillos de adobe, impidiendo las filtraciones de agua de lluvia; sin embargo, precisamente la ausencia de humedad, los hacía muy vulnerables a la erosión eólica, apreciándose una paulatina pérdida de tierra en las crestas de los muros que hacía peligrar su conservación en un futuro no muy lejano. Por ello, el Plan incluía un estudio detallado de todos los alzados para proceder a su conservación inmediata.

Otra actuación importante era la restitución de los muros de adobe y piedra arrasados por el dueño del terreno en el sector meridional del yacimiento (Lám.V). Para ello se proponía la elaboración de adobes de distinta composición que los construidos en el edificio y el montaje de las grandes piedras dispersas por el entorno del yacimiento procedentes del monumento. Así mismo, se contemplaba la reposición de los suelos rojos y blancos que dominaban el interior del monumento. Una vez analizada la composición de estos, se vio que los pavimentos estaban hechos a base de caolines que procedían de un yacimiento cercano a la localidad de Zalamea de la Serena, lo que facilitaba enormemente la restitución. También se contemplaba la restitución de las pizarras del patio, algunas muy deterioradas, hallándose una cantera de idénticas características a las de Cancho Roano en una localidad situada a menos de $15 \mathrm{~km}$ del enclave protohistórico. Finalmente, también se incluía la restauración de la muralla y torres, así como la del dique que frenaba la crecida del arroyo, totalmente enterrado y descubierto en las últimas campañas.

Por último, se incluía una actuación especial para conservar los restos constructivos del edificio que se organizaba inmediatamente debajo del actual, del que habíamos exhumado su fachada principal con el vano de entrada y con los alzados de adobe enlucidos de caolín rojo y blanco y conservados en más de un metro de altura en algunos de sus tramos. Tanto esta amplia zona del segundo edificio como la cámara principal donde se halló un altar en forma de piel de buey extendida, merecían ser conservadas y expuestas para la visita gracias a su monumentalidad y a la viveza de sus suelos y enlucidos.

\subsection{El proyecto de investigación}

El desarrollo del proyecto de investigación iba, como es lógico, muy unido a los descubrimientos que pudieran producirse en las excavaciones pro- 
gramadas, sin embargo, se planteaban una serie de necesidades que se antojaban esenciales para conocer a fondo el yacimiento; así, se introdujo el estudio del paleopaisaje del entorno mediante los análisis antracológicos, polínicos y carpológicos; también se incluía la analítica de los metales, las cerámicas y las tierras, amén de conseguir baterías de C-14, estudios litológicos de los materiales utilizados, etc. Por último, se planteó la necesidad de estudiar todos los fondos depositados por Maluquer en las campañas dirigidas por él tanto para estudiar el numeroso material inédito como para revisar otros de los que ahora se podría sacar mayor partido en función de las técnicas antes enumeradas.

\subsection{Documentación}

Una de las partidas más altas que se solicitaban tenía como objetivo realizar una completa planimetría de todos los restos arquitectónicos exhumados para así poder elaborar con todas las garantías las diferentes plantas de los tres edificios documentados y de las diferentes fases constructivas que mostraban cada uno de ellos. Para ello se solicitó el concurso de un arquitecto que desarrollaría esa labor en las campañas de excavación acompañado de un equipo de arqueólogos. Igualmente, se requería la presencia de un fotógrafo profesional para realizar un reportaje de cualquier aspecto arquitectónico del yacimiento, completándose con la aplicación de un programa informático que permitiera la restitución ideal de los edificios y su pormenorizado estudio.

\subsection{Difusión}

Siguiendo la pauta marcada por Maluquer, creímos imprescindible que todos estos trabajos se fueran difundiendo a medida que se iban agotando los diferentes sectores del último complejo monumental, para después acometer el estudio exhaustivo de todos los materiales recuperados en esas excavaciones y, por último, dar a conocer los resultados de las excavaciones de los edificios más antiguos. Estas publicaciones, editadas como las clásicas memorias de excavación, irían acompañadas de diferentes artículos que anticiparían los hallazgos más significativos que fueran surgiendo, además de otros de carácter mucho más divulgativo en revistas no es- pecializadas para conseguir la atención del público interesado en el lugar. Todos estos escritos se compaginarían con charlas y conferencias tanto en centros especializados nacionales e internacionales como en institutos, centros culturales y colegios de la comarca, más involucrados con el yacimiento y donde había que esforzarse para conseguir el mayor grado de sensibilización entre sus habitantes.

Por último, aunque sin entrar en detalles presupuestarios, sino tan sólo a modo de sugerencia, se proponía que tras la ejecución de todos estos apartados, la Junta debería plantearse la posibilidad de construir un museo u otro tipo de centro frente al yacimiento donde pudieran exponerse algunas fotografías, planos y piezas procedentes de la excavación que sirviera de introducción al visitante. Igualmente se hacían algunas consideraciones sobre el camino más idóneo para acceder al yacimiento y la expropiación de los terrenos tanto para construir el mencionado museo como para abrir la nueva comunicación para los coches. Igualmente, se aconsejaba la elaboración de una guía divulgativa así como la realización de un CD ROM donde se recogieran los avatares históricos del yacimiento y se explicara de forma generalizada las diferentes funciones del enclave.

\section{PRIMERA FASE DE EJECUCIÓN}

Otra circunstancia imprevisible impulsó la ejecución del Plan Integral de Cancho Roano. Gracias a un programa «Leader» de la Unión Europea, concedido a la Mancomunidad de Municipios de la Serena y gestionado por el Centro de Desarrollo Regional (CEDER) de esta comarca, donde se contemplaban actuaciones relacionadas con el patrimonio arqueológico de la zona, pudimos desarrollar algunos de los proyectos recogidos en el Plan Integral.Además, el propio CEDER impulsó un convenio de colaboración con la Junta de Extremadura, firmado en 1996, para así aumentar la dotación presupuestaria para el yacimiento, siempre dentro de las actuaciones especificadas en el Plan Integral.

En esta actuación a dos bandas confluían sendos intereses de las instituciones implicadas. Por un lado, la Junta de Extremadura veía un camino para desarrollar el Plan aprobado, pero además, con el concurso del proyecto europeo se podría rebajar sensiblemente los plazos estimados para la culminación de los trabajos enumerados. Por otro lado, la Mancomunidad conseguía no sólo implicarse

T. P., 57, n. ${ }^{\circ} 2,2000$ 
directamente en el yacimiento arqueológico más señero de esta zona, sino que además avivaba su ejecución para disponer en el menor tiempo posible de un monumento que estaba llamado a ser el eje de sus recursos arqueológicos, basados en otros monumentos también de gran importancia diseminados por esta comarca natural y que podrían potenciarse bajo la atracción del propio Cancho Roano. De hecho, la Mancomunidad ha comenzado a invertir en otros yacimientos cercanos que en el futuro conformaran una ruta arqueológica de una gran riqueza histórica y patrimonial.

Pero a pesar de la fuerte inversión, concebida en dos fases de un año cada una, no era posible acometer todos los proyectos incluidos en el Plan Integral, por lo que se eligieron las actuaciones más urgentes o de mayor interés para desarrollar este programa.

\subsection{Excavación arqueológica}

Conseguimos que se diera prioridad a la excavación tanto de todo el interior del edificio principal, para extraer las plantas de los santuarios más antiguos, como del foso que rodeaba al complejo arquitectónico. Pero el gasto que suponían estas intervenciones necesitadas de amplios equipos técnicos y de estudiantes de apoyo durante varios meses, mermaba considerablemente el presupuesto general del programa europeo. Por ello, consideramos favorablemente la participación de la flamante EscuelaTaller de Arqueología «Isla del Zújar», ubicada en la cercana localidad de Castuera y dependiente precisamente de la Mancomunidad de Municipios de la Serena. La experiencia fue un éxito, destinándose los alumnos a la zona menos complicada de la excavación, el foso, donde realizaron sus prácticas obligatorias mientras agotaban buena parte de su trazado; además, limpiaron y clasificaron las cerámicas exhumadas, por lo que el ahorro fue bastante considerable.

\subsection{La compra de terrenos}

Gracias a la buena disposición de los dueños de los terrenos colindantes al yacimiento, una de las primeras actuaciones fue la compra de esos terrenos, necesarios para realizar tanto la excavación del sector occidental del foso como para disponer de un espacio suficiente que permitiera la visita desahogada del yacimiento.

\subsection{El cerramiento}

Otra actuación urgente era la ejecución de un nuevo cierre de la propiedad pública, pues el existente no sólo estaba muy deteriorado sino que además no cubría el reciente terreno adquirido. También en este caso pudimos paliar considerablemente el coste de su ejecución; así, mientras la cimentación fue contratada dentro del proyecto de ejecución de la obra, la realización de las verjas y puertas fue encomendada a la Escuela-Taller de cerrajería ubicada en Zalamea de la Serena, lo que sin duda supuso otro sustancial ahorro para el programa europeo.

\subsection{Restauración y conservación}

Uno de los motivos principales que se adujeron para la intervención inmediata en Cancho Roano era el deterioro que estaban sufriendo los alzados de adobe del edificio principal, por ello, se encargaron inmediatamente varios estudios para proceder a su consolidación. La tarea no fue nada fácil dada la carencia de especialistas en este tipo de construcción, pero por fin pudimos contar con la desinteresada colaboración del Servicio de Patrimonio de la Comunidad de Murcia, cuyos técnicos, con una dilatada experiencia en construcciones de tierra en la zona centroamericana, nos facilitaron la fórmula más adecuada para la protección de los adobes y que podemos decir al día de hoy que ha dado un resultado verdaderamente extraordinario, siendo evidente tanto su consolidación como su protección ante la erosión eólica a la que siempre estarán expuestos.

Otra actuación importante era la restauración del sector meridional del edificio principal, arrasado por las labores agrícolas del antiguo propietario (Lám. VI). Para ello se realizaron unos 5000 adobes con tierra diferente a la empleada en los ladrillos del edificio original para, posteriormente, ser montados sobre los cimientos conservados de esa zona. A la vez, se restituyó la parte de la terraza derruida, así como algunos tramos del paseo de guijarros que se organizaba sobre la muralla oriental. En una segunda fase, se consolidaron los suelos y los canales que cruzaban los pasillos perimetrales para desembocar en el foso, se restituyeron los suelos de arcilla roja que pavimentaban el edificio, previo enterramiento de los restos de los edificios más antiguos y, finalmente, 


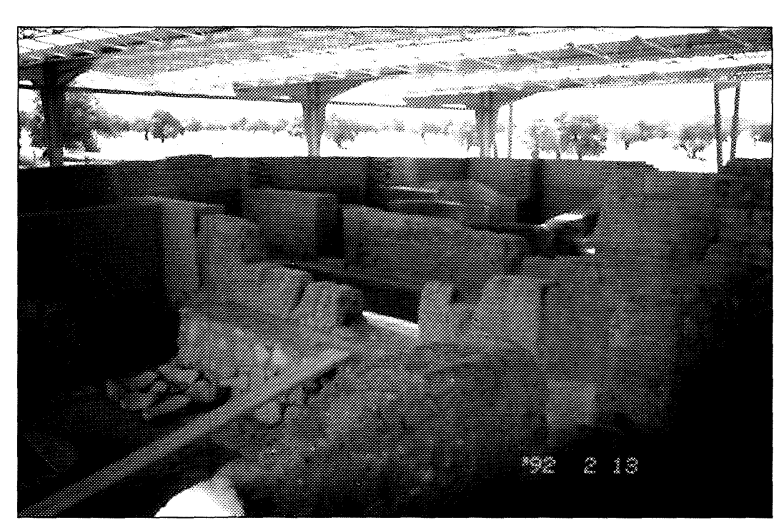

Lám. VI. Vista de la zona meridional del monumento de Cancho Roano tras su restitución.

se excavó totalmente el dique sobre el arroyo Cigancha.

Por último, se decidió conservar la fachada oriental del segundo santuario, organizada bajo la habitación número 2 . Se pretendía con ello conservar un muro bastante bien conservado que a la vez permitía descubrir al futuro visitante una buena parte de ese edificio anterior, donde además se apreciaba el vano del acceso principal. Pero para ello necesitábamos no sólo restituir parte de su trazado, sino, y lo que era más importante, consolidar los cimientos de las paredes de $\mathrm{H}-2$, pues los restos se hallaban a una profundidad considerable y no se podían dejar los cimientos desnudos. Se optó por construir sendos muros de ladrillo que protegieran la cimentación y forrarlos de madera para darles mayor prestancia; de nuevo tuvimos la ocasión de poder colaborar con otra Escuela-Taller de Zalamea de la Serena, en este caso con la de carpintería, que se encargó de la entibación de este espacio. Parecía que con todas estas actuaciones, una vez realizadas en su totalidad, el edificio podía estar listo para proceder a su apertura para la visita pública.

\subsection{Divulgación}

Todas estas actuaciones coincidieron con la finalización del estudio de los sectores Este, Oeste y Sur del yacimiento, por lo que el propio programa desarrollado bajo el convenio antes mencionado se encargó de la publicación de las tres memorias de excavación. Por último, se encargó la realización de una maqueta a escala 1: 100 para ser expuesta en los ayuntamientos de centros culturales de la zona.

\section{SEGUNDA FASE DE EJECUCIÓN}

Cuando aún no habíamos finalizado la primera fase de actuación, en el verano de 1997, y al calor de la presentación de las memorias de las excavaciones, el Consejero de Cultura de la Junta de Extremadura y el Presidente de la Mancomunidad de Municipios de la Serena, ante la monumentalidad que había adquirido el complejo arquitectónico y acogiéndose a un flamante proyecto de desarrollo para la comarca de La Serena, se comprometieron a realizar un esfuerzo final para llevar a cabo las intervenciones más costosas. Estas eran la nueva cubierta de protección del yacimiento, el centro de interpretación, la compra de los terrenos de la otra orilla del arroyo por donde discurriría el nuevo camino y donde se instalaría el propio centro de interpretación con los servicios necesarios y, por último, la construcción de un puente para comunicar ambas zonas, así como la adecuación definitiva del yacimiento para la visita. Por último, se contemplaba la excavación total del foso en el plazo de un año, además de la conclusión de algunas zonas donde no habíamos podido intervenir por las obras que veníamos realizando.

En esta ocasión, los diferentes proyectos no estaban sometidos a convenio, sino que se decidió que cada institución se hiciera cargo de una actuación concreta para así agilizar los trámites, todas las intervenciones se desarrollarían en dos años, por lo que la ejecución definitiva las obras deberían estar finalizadas en octubre de 2000.

La Mancomunidad de Municipios de la Serena, a través de un nuevo programa europeo, en esta ocasión un Programa Interregional (INTERREG) de la Diputación Provincial de Badajoz, consiguió los fondos para hacerse cargo del montaje de la nueva cubierta, la construcción del puente sobre el arroyo Cigancha, la compra de los terrenos donde se levantaría el centro de interpretación y por donde discurriría el nuevo camino hacia el yacimiento y, por último, las obras necesarias para adecuar el yacimiento para la visita pública.

Por su parte, la Junta de Extremadura, a través de la Dirección General de Patrimonio de la Consejería de Cultura, aprobó un crédito extraordinario para los dos años en los que se contemplaba: la construcción del Centro de Interpretación, la excavación definitiva del interior del edificio principal y de todo el foso, las acometidas de agua y luz y el estudio arqueológico del yacimiento, así como la publicación de las memorias y guías divulgativas del enclave.

T. P., 57, n. ${ }^{\circ} 2,2000$ 


\subsection{La excavación arqueológica}

La primera intervención que se llevó a cabo con el nuevo Programa de actuación fue la excavación del foso que rodeaba el complejo monumental, del que aún quedaba por exhumar todo su tramo occidental y meridional, unos $60 \mathrm{~m}$ en total. Esta intervención sólo podía acometerse con un amplio equipo de técnicos y estudiantes que ahora fue posible formar gracias al presupuesto aprobado (Lám. VII). Estas excavaciones, así como el estudio de la enorme cantidad de material hallado en su interior y el análisis de la numerosa fauna depositada en el fondo del foso, han finalizado recientemente, quedando sólo pendiente para este verano algunos espacios del interior del edificio y el sector sur del pasillo perimetral, donde se instalará una pasarela para la visita.

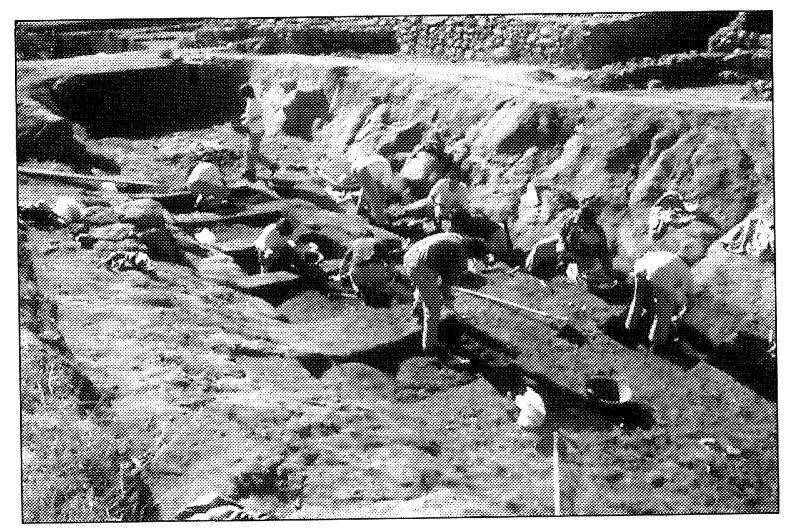

A

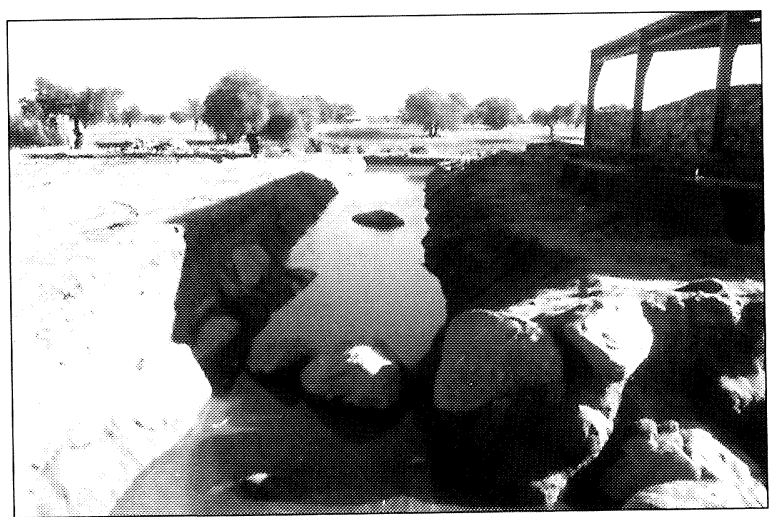

B

Lám. VII. A) Excavación de los primeros niveles del foso que rodea el complejo arquitectónico. B)Aspecto actual del foso tras su excavación integral.

\subsection{La cubierta}

Los propios servicios de la Consejería de Cultura acometieron el proyecto de cubrición de los restos de Cancho Roano, proyecto que se ejecutó en el invierno del 2000. La nueva cubierta debía solventar las carencias que sufría el yacimiento desde hacía años, al haberse exhumado unos $500 \mathrm{~m}^{2}$ más de estructuras arquitectónicas que se estaban deteriorando peligrosamente al estar expuestas a la intemperie. Los extremos de la nueva estructura metálica vierten al foso, con lo que además se consigue que éste mantenga el mayor tiempo posible una lámina de agua que lo acerque lo más posible a su aspecto original. También se decidió que la nueva cubierta fuera más alta que la anterior para solventar la pérdida de visibilidad de los restos al instalar una mayor masa aérea sobre el monumento (Lám.VIII). Para la insta-

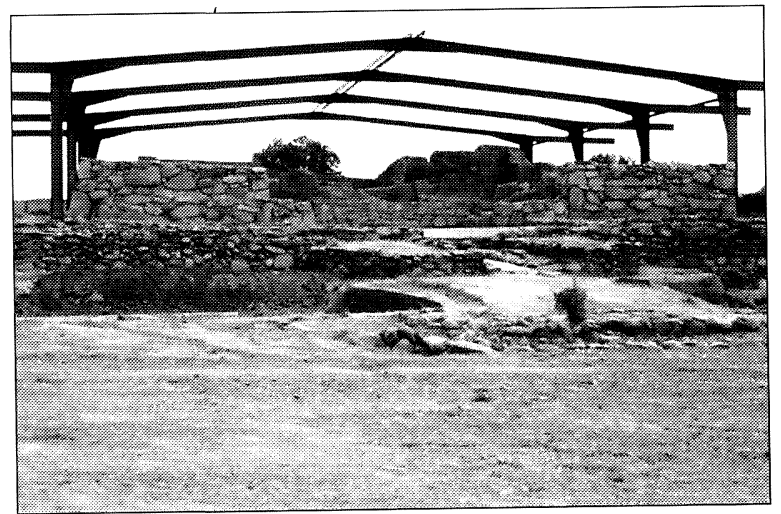

A

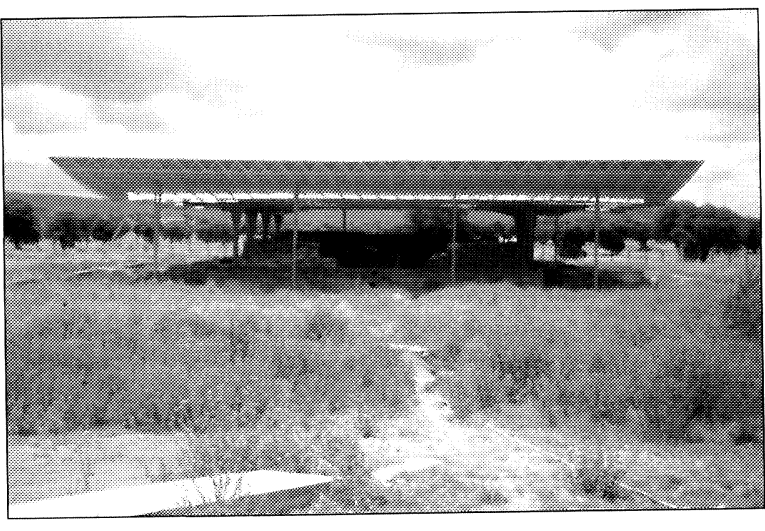

B

Lám. VIII. A) Proceso de instalación de la nueva cubierta de protección. B) Aspecto actual de Cancho Roano tras su instalación. 


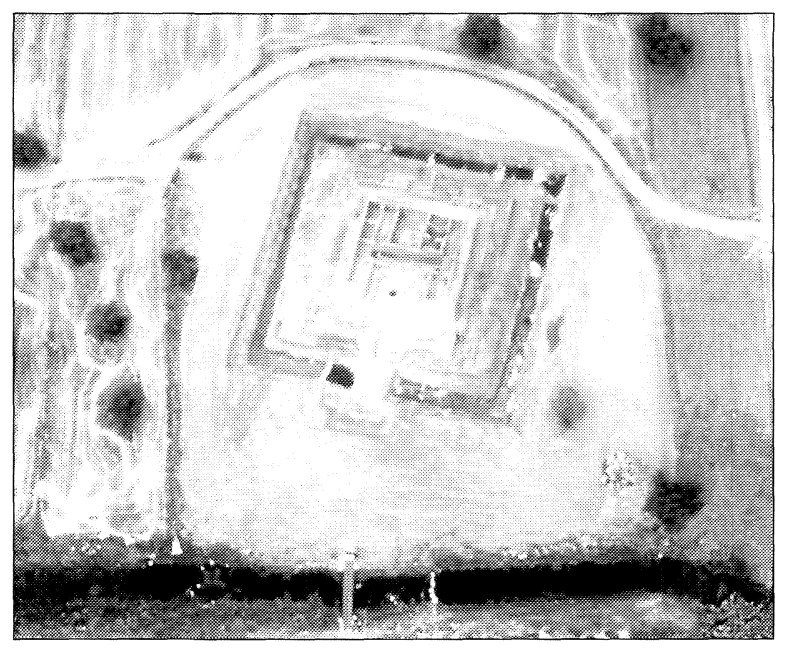

Lám. IX. Fotografía aérea del santuario de Cancho Roano tras la retirada de la antigua cubierta.

lación de los pilares que la soportan, así como de las tirantas que los unen entre sí, hubo que levantar las rampas de arcilla roja de los sectores Este y Oeste, hoy totalmente restituidas con las tierras originales.

Antes de retirar la antigua cubierta e instalar la nueva, habíamos solicitado un intervalo de tiempo de dos días para poder realizar fotografías aéreas del yacimiento (Lám. IX), para lo que se contrató los servicios de un helicóptero que además permitía hacer tomas verticales y desde varios ángulos para así completar el reportaje fotográfico que habíamos elaborado del complejo arquitectónico.

\subsection{El Centro de Interpretación}

También han sido los servicios de la Consejería de Cultura de la Junta de Extremadura los encargados de realizar tanto el proyecto de obra del centro de interpretación, elaborado por el arquitecto T. Martín Solo de Zaldívar, quien también había diseñado la nueva cubierta, como el de su contenido, realizado por Guillermo Kurtz y Coronada Domínguez de la Concha del MuseoArqueológico de Badajoz.

La idea de centro de interpretación escogida para Cancho Roano, dentro de las diversas definiciones existentes hoy en día para estos centros, es la que defiende que el objetivo último del mensaje es el propio yacimiento, su evolución, valor y, sobre todo, su significado. Se parte de la base de que el yacimiento está ubicado frente al centro, por lo que el discurso debe girar en torno a la explicación de su funcionamiento y los materiales que contenía, pues su carácter monumental y su definición arquitectónica serán patentes cuando el interesado inicie la visita al yacimiento una vez haya comprendido en el centro de interpretación la importancia de los restos que va a observar.

Los objetivos planteados para el centro son los siguientes: servir de apoyo a la visita del yacimiento, generar una idea global de su naturaleza, situar Cancho Roano en su contexto histórico, geográfico y cultural, explicar las diferentes partes de que consta el monumento, informar de las actividades que se desarrollaban en torno al monumento, transmitir la impresión de la antigua religiosidad, informar sobre los edificios más antiguos que justifican la existencia del último santuario e indicar el proceso arqueológico de investigación desde su descubrimiento. Se pretende así que el visitante salga del centro de interpretación con una noción general de las diferentes partes del yacimiento y una comprensión, aunque sea somera, de su estructura integral. También se pretende transmitir que Cancho Roano es el producto de una cultura compleja inserta en un mundo también complejo aún no muy bien conocido, donde la religiosidad y sus rituales juegan un papel fundamental, pero asociados a otras funciones muy bien definidas en el monumento.

Otro de los objetivos del centro es ofrecer al espectador elementos expositivos de gran formato, tanto para facilitar y acelerar la percepción de los diferentes elementos expuestos, como para crear un efecto impactante proporcional al que causaría el monumento en su origen. Por último, se pretende también crear un alto grado de sobrecogimiento en el espectador para que éste se identifique con facilidad con el ambiente de religiosidad que emanaba del santuario. Para todo ello se van a utilizar tres recursos principales: una maqueta interactiva con sonido y luces, paneles gráficos donde en forma de collage se transmita el contenido del monumento $y$, por último, la reconstrucción de algún ambiente del santuario con piezas originales y reproducciones.

En cuanto al discurso de la exposición, el proyecto contempla el desarrollo de ocho unidades independientes: la primera, en el vestíbulo de entrada, se centra en la narración de la historia de la investigación del yacimiento, con una reconstrucción de su última fase constructiva. La segunda unidad contextualiza Cancho Roano con el conjunto de las culturas mediterráneas de ese momento. Las diferentes actividades de Cancho Roano se exponen en la tercera unidad. En la cuarta unidad se desarrollan 


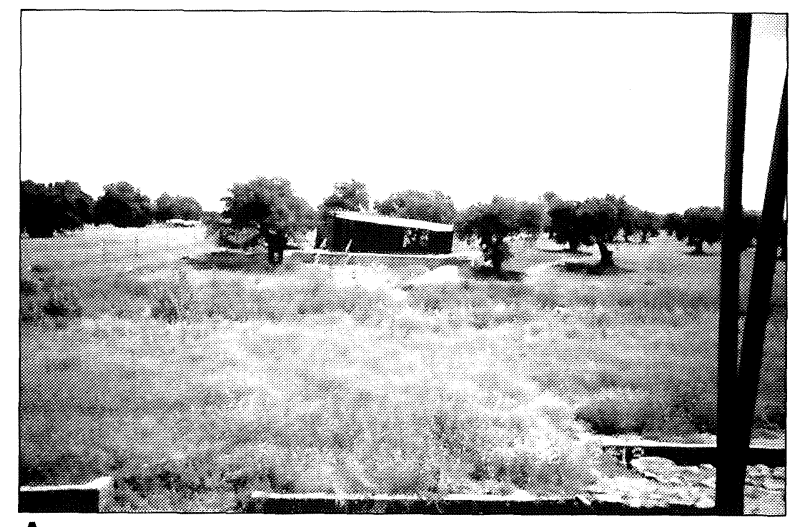

A

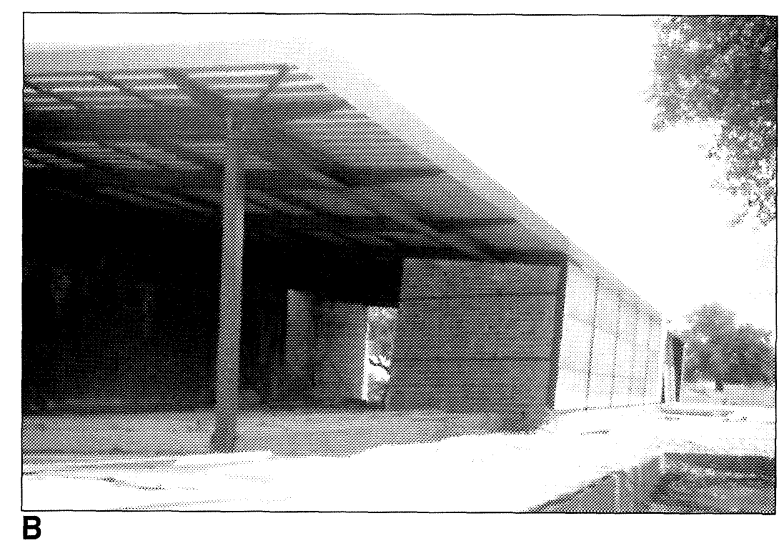

Lám. X.A) Vista de las obras del Centro de Interpretación desde el santuario, al otro lado del arroyo Cigancha. B) Detalle del Centro de Interpretación, aún en fase de ejecución.

los elementos y estructuras que conforman el propio yacimiento. La siguiente unidad está protagonizada por la maqueta, donde se explica con mayor detalle el yacimiento. La sexta unidad trata de explicar la superposición de edificios y su proceso histórico. La séptima unidad es la única que trata de recrear la idea de religiosidad del enclave con el montaje de uno de los altares del santuario. Por último, en la octava unidad, que incide en esa fundamental vertiente religiosa del sitio, se presenta la reconstrucción con materiales originales de una de las cámaras perimetrales del complejo, donde se hallaron las ofrendas al santuario.

Por lo que respecta al edificio del Centro de Interpretación, como ya se ha apuntado, se ubica frente al yacimiento, al otro lado del arroyo Cigancha, a unos $80 \mathrm{~m}$ de distancia (Lám. X). Se levanta entre tres grandes encinas, y su fachada occidental, totalmente acristalada, permite tener siempre una referencia del complejo arquitectónico, lo que facilita la comprensión tanto del entorno como de la organización espacial del monumento. La conclusión de las obras, hoy muy avanzadas, deben estar finalizadas en el próximo otoño, y antes de que finalice el 2000 debería estar concluido el montaje de la exposición.

\subsection{La adecuación}

La última actuación prevista en el yacimiento es precisamente su adecuación para facilitar la visita pública. Las características del yacimiento y la necesidad de preservar intactos los restos constructivos exhumados obligan a establecer diferentes itinerarios cuyo objetivo es proporcionar al visitante algunas alternativas para observar los restos y así comprender la complejidad del santuario. El objetivo del proyecto es, por lo tanto, acercar al visitante al edificio sin transitar por él. Se han elaborado tres itinerarios principales: el primero discurre por la terraza del santuario que rodea todo el monumento, con este circuito el visitante podrá admirar tanto las estancias interiores como las construcciones perimetrales externas. Como sólo existe una posibilidad de acceder al monumento por su entrada oriental, donde se encuentra una estela de guerrero, se ha proyectado un paseo de madera que atraviesa todo el patio oriental para que el pavimento de arcilla roja de éste no se deteriore con el tránsito. El segundo itinerario discurre en un nivel más bajo, por el pasillo perimetral, con lo que el visitante tendrá una visión pormenorizada de las capillas perimetrales. A la vez, y por su derecha, estará flanqueado por la gran terraza de piedra que proporcionará la sensación de monumentalidad. El tercer circuito se ha proyectado en torno al foso, que delimita y aísla al santuario. Con este itinerario se pretende dar una visión de conjunto del complejo que, mediante un sistema de barreras, garantizará la seguridad del enclave.

Todos estos itinerarios estarán debidamente señalizados, utilizándose la misma pauta informativa que la desarrollada en el Centro de Interpretación para mantener una coherencia estética y didáctica. Los soportes informativos, situados en los puntos de entrada y salida, tendrán dos funciones, una de carácter orientativo, y otra más indicativa, con la intención de proporcionar al visitante información sobre los contenidos de las diferentes estancias que vaya viendo, a la vez que sirven de nexo entre el yacimiento y lo expuesto en el Centro de Interpretación. En los paneles figurará siempre la planta general del yacimiento, destacándose la zona visi- 
tada en ese momento, la definición de dicha zona, una breve explicación de la misma y una ilustración gráfica complementaria.

La última fase de actuación se centrará en la consolidación de algunos muros, la reparación de los suelos afectados por las obras, así como la limpieza general del yacimiento, donde se plantarán junto al arroyo los fresnos que hasta hace poco se erguían en sus orillas, así como la replantación de varias encinas, taladas en los últimos años para facilitar las labores arqueológicas.

Por último, se han acometido varias obras de infraestructura para introducir el agua y la luz en el centro de interpretación, al tiempo que se ha construido un nuevo camino de entrada al yacimiento previa compra de los terrenos afectados. Con ello se pretende que el acceso se haga directamente al centro de interpretación, donde se dejarán los vehículos; posteriormente, y tras cruzar el puente de madera instalado sobre el arroyo, se alcanzará el complejo monumental.

\subsection{La difusión}

Esta es quizás una de las labores en la que se ha puesto más empeño en los últimos años, aunque hay una considerable desproporción entre la difusión científica editada hasta el momento y la divulgación. Por ello, en el proyecto se recoge la necesidad de editar tres publicaciones de carácter científico, donde se estudien los resultados de las excavaciones de los últimos años y los materiales procedentes del yacimiento, desde las primeras excavaciones hasta nuestros días. Por otra parte, y coincidiendo con la apertura del yacimiento y el centro de interpretación a la visita pública, se contempla la necesidad de editar dos guías sobre el santuario, una completa, donde se aborde toda la problemática del lugar, y otra mucho más esquemática que se ceñirá a una somera descripción de las estructuras y de los materiales más significativos hallados en el interior. Con ellas se intenta dar respuesta a las diferentes demandas de los visitantes. Por último, se encargará en breve la realización de un CD-ROM, también de carácter divulgativo, cuyo destino final, además de su venta al público, está pensado para abastecer a las instituciones educativas de la región y de otros centros que lo soliciten. Ha quedado abierta también la posibilidad de que la iniciativa privada pueda realizar reproducciones, gráficos, etc. de algunos materiales destacados del yacimiento, siempre bajo la supervisión y permiso de la Junta de Extremadura.

\section{ESTRATEGIA DE FUTURO}

En definitiva, las circunstancias que han permitido el desarrollo de los sucesivos proyectos de Cancho Roano son una consecuencia de la propia inercia científica del enclave, pues en la gran inversión realizada nunca se ha tenido en cuenta ni el potencial demográfico o turístico de la zona, ni la accesibilidad al enclave, aunque, evidentemente, ha jugado un papel fundamental su monumentalidad. Por el contrario, el santuario protohistórico está siendo el gran impulsor de la explotación y adecuación de otros enclaves de la comarca que, en un futuro no muy lejano, conformarán una ruta arqueológica realmente privilegiada para los interesados en el turismo cultural de calidad.

Al amparo de los resultados obtenidos, recientemente se han solicitado dos nuevos Proyectos de Investigación, el primero del Plan Nacional I + D con Fondos Estructurales de Desarrollo Regional (FEDER) de la Unión Europea. Este proyecto, ya en marcha y con una duración de tres años, trata de resolver uno de los aspectos más importantes que siempre nos ha planteado Cancho Roano, su razón de ser en ese enclave determinado. Por ello, el proyecto se basa en la prospección intensiva de su entorno inmediato y la sistemática de la comarca de La Serena, para posteriormente elaborar un SIG de la zona y reproducir su paleoambiente. El segundo proyecto, también con una duración de tres años y dentro de los I + DT (Investigación y Desarrollo Tecnológico) de Extremadura, consiste en solventar aspectos más específicos del propio yacimiento, con una fuerte base analítica que nos ayude a descifrar algunas de las incógnitas que aún nos ocupan.

\section{BIBLIOGRAFÍA}

La amplia bibliografía existente sobre Cancho Roano está recogida en las tres últimas memorias de excavación hasta ahora editadas:

Celestino, S. (ed.) (1996): El Palacio-Santuario de Cancho Roano. Los sectores Oeste, Sury Este. Publicaciones, 3. Museo Arqueológico de Badajoz. Madrid.

Celestino, S. (1997): "Santuarios, centros comerciales y lugares sacros". Espacios y lugares cultuales en el mundo ibérico. Quaderns de Prehistòria i Arqueologia de Castelló, 18: 359-389.

T. P., 57, n. ${ }^{\circ} 2,2000$ 